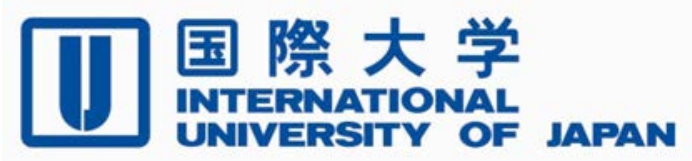

Economics \& Management Series

EMS-2014-03

\title{
To Bond or to Bridge? Contingent Effects of Man- agers' Social Capital on Organizational Performance
}

Sangyub Ryu

International University of Japan

March 2014

IUJ Research Institute

International University of Japan

These working papers are preliminary research documents published by the IUJ research institute. To facilitate prompt distribution, they have not been formally reviewed and edited. They are circulated in order to stimulate discussion and critical comment and may be revised. The views and interpretations expressed in these papers are those of the author(s). It is expected that the working papers will be published in some other form. 
To Bond or to Bridge?

Contingent Effects of Managers' Social Capital on Organizational Performance

\section{Sangyub Ryu}

Public Management and Policy Analysis Program

Graduate School of International Relations

The International University of Japan

777 Kokusai-cho, Minami Uonuma-shi

Niigata, 949-7277, Japan

Email: sangyubr@iuj.ac.jp 


\begin{abstract}
A top manager's social capital is considered as a critical resource for determining organizational outcome. However, little is known about the impacts of social capital on public organizations' performance. By dimensionalizing social capital into two, this study investigates impacts of a superintendent's bonding and bridging social capital on the performance of school districts. Findings show that bridging social capital has positive impacts on organizational performance but in a time of financial difficulty, it worsens negative shocks of financial difficulty. Bonding social capital is found to be exactly the opposite. This study argues that bonding and bridging social capital is not an "either-or" question and top managers are required to balance the two contingent on the situation that their organizations face.
\end{abstract}

Key words: bonding, bridging, social capital, performance

\title{
INTRODUCTION
}

A number of organizational studies have emphasized social capital, in addition to physical or human capital (Coffe and Geys, 2007; Coleman, 1988; Putnam, 2000). However, there is a lot about the role of social capital in public management that we do not know. One core question to be answered is the impact of social capital on organizational outcome. It has been believed that social capital produces positive externalities on society (Halpern, 2005). However, recent studies make a counterargument that social capital does not guarantee to produce positive outcomes (Coffe and Geys, 2007; also, see e.g. Bourdieu, 1985; Coleman, 1988; DeFilippis, 2001; Foley and Edwards, 1998; Olson, 1982). The acknowledgement that social capital possibly results in negative outcomes has led scholars' attention to identify various types of social capital; that is, social capital is a concept with multiple dimensions and, depending on the dimensions of social capital, it produces positive or negative externalities (Coffe and Geys, 2007; Putnam, 2000). Some identify internal social capital and external social capital (Leana and Pil, 2006) while others identify homogeneous networks and heterogeneous networks (Coffe and Geys, 2007). Although their terms are different, the core ideas do not deviate from what Putnam (2000) calls bonding social capital and bridging social capital. Bonding social capital 
is related to closed networks comprising of people/institutions with similar background while bridging social capital is associated with connections of people/institutions with dissimilar backgrounds (Marshall and Stolle, 2004). What is commonly argued is that bridging social capital is more likely to produce positive outcomes than bonding social capital (Coffee and Geys, 2007; Marshall and Stolle, 2004). Despite the efforts to make theoretical distinctions between bonding social capital and bridging social capital, the current body of knowledge on social capital in the field of public management is at best underdeveloped for its operationalization and empirical causal relationships (Coffe and Geys, 2007).

This study aims at operationalizing bonding and bridging social capital in the context of public education and analyzes effects of each social capital on organizational performance. The expected and empirically found causal relationships from this study are that a top manger's bridging social capital enhances organizational performance while bonding social capital decreases organizational performance. However, in a time of difficulties (e.g., unusual financial deficit), bridging social capital may not operate well enough to protect an organization's core functions as compared to bonding social capital. To analyze contingent effects of social capital on organizational performance, Granovetter's (1973) strength of weak ties and Krackhardt's (1992) strength of strong ties are discussed. This study makes theoretical contributions in that it unravels dimensions of social capital - the bonding and bridging role- and different effects of each dimension contingent on the level of environmental uncertainty. The theoretical implication is that to bond or to bridge is not an "either-or" question; rather, there exists an equilibrium between the two based on the environments that organizations face, and thorough analyses on bonding and bridging social capital as well as the environments need to follow to maximize 
organizational performance.

This study is organized as following. First, general literature on social capital and organizational performance is reviewed followed by literature on bonding and bridging social capital associated with organizational performance. Then, roles of social capital in a time of difficulties are discussed. This study adopts and modifies O’Toole and Meier's (1999) contingent model to empirically explore impacts of a superintendent's bonding and bridging social capital contingent on a school district's financial difficulties. Thus, the original model and the modified model as well as data and variables will be presented followed by statistical analysis. At the end, this study closes with concluding and discussing remarks to evaluate the theoretical contribution of this study and to promote future research.

\section{SOCIAL CAPITAL AND ORGANIZATIONAL PERFORMANCE}

Although much attention has been given to social capital, the concept of social capital is not well accepted yet, and the term has been used differently. Coleman (1988) defines social capital as "a variety of different entities, with two elements in common: they all consist of some aspect of social structure, and they facilitate certain actions of actors — whether personal or corporate actors—within the structure” (598) whereas Bourdieu (1986) defines social capital as the "aggregate of the actual or potential resources which are linked to possession of a durable network of more or less institutionalized relationships of mutual acquaintance and recognition — or in other words, to membership in a group — which provides each of its members with the backing of the collectivity-owned capital, a 'credential' which entitles them to credit, in the various senses of the word” (249). Or, a simple version of Putnam’s (2000) definition of social capital is "connections among individuals—social networks and 
the norms of reciprocity and trustworthiness that arise from them” (19). Although different angles capture different aspects of social capital, the core idea of social capital emphasizes both the network of individuals/organizations and the values (contents) that are transferred through the network to create competitive advantage to accomplish goals of individuals or groups of individuals (Bourdieu, 1986; Burt, 1992; 2002).

Social capital is closely associated with an organization's economic outcomes. Social capital provides organizational members with "a valuable resource for the conduct of social affairs" and facilitates "some form of social action while inhibiting others” (Nahapiet and Ghoshal, 1998. p. 245). As a result, social capital produces a unique social structure where a certain level of economic transactions can be saved. For instance, principal-agent relations necessitate costly contracts for the principal to control his/her agent's behavior which results from asymmetric information and moral hazard. The basic assumption behind the principal-agent relations is that an agent has more information than a principal so that the agent can take opportunistic actions and, to correct the agent's opportunism, the principal is willing to pay for precise contract writing or monitoring (Moe, 1984). However, social capital develops a high level of trust between a principal and an agent so that social capital shared by both the principal and the agent decreases the likelihood of the agent's opportunism as well as the principal's need to monitor the agents (Nahapiet and Ghoshal, 1998; Putnam, 1993). Thus, both a principal and an agent can be economically better off when they are in a well-established social capital scheme. This is one of the appealing arguments of why one expects positive links between social capital and organizational productivity. 
According to Putnam (2000), social capital has two aspects: individual and collective. On the one hand, individuals form networks with others who may have some necessary resources that the individuals do not have but are desperate to have; then, individuals can take advantage of the networks for their own interests (Putnam, 2000). A top manager’s social capital helps in obtaining necessary resources through his/her social networks, which, in turn, improves the top manager's performance. On the other hand, an individual-level social capital can generate externality -positive or negative- that can influence the wider community, which the individual does not intend (Putnam 2000). For instance, a top manager’s strong social capital with reputable people, which is basically formed for the sake of the top manager, may lead to a better organizational reputation and appeal to the clients of the organization.

Although recent literatures as well as empirical research on social capital have focused on the positive outcomes of social capital (Coffe and Geys, 2007), a negative side of social capital should be considered as well. For instance, terrorist organizations clearly hold a strong social capital but do not generate positive externalities for the wider community (Coffe and Geys, 2007). To identify these positive and negative impacts of social capital, efforts have been made recently to distinguish between bonding and bridging social capital (Putnam, 2000).

\section{BONDING SOCIAL CAPITAL, BRIDGING SOCIAL CAPITAL AND}

\section{ORGANIZATIONAL PERFORMANCE}

Social capital is a multi-dimensional concept and bonding and bridging social capital are perhaps the most important dimensions among others (Putnam, 2000). According to Coffe and Geys (2007), the critical aspect to distinguish between the two lays in the different types of socializing. However, only a little empirical research has been conducted to separate the effects of bonding and bridging social capital (Coffe and 
Geys, 2007). The following discusses possible causal relationships between bonding and bridging social capital and organizational performance.

\section{Bonding Social Capital and Organizational Performance}

Bonding social capital is a network of individuals with a homogenous background, and it tends to be inward looking and clearly distinguishes between inside and outside the boundary of the network (Putnam, 2000). Bonding social capital forms closed networks and members in the closed networks share high levels of trust and reciprocity (Coffe and Geys, 2007). As a result, organizational members with bonding social capital would show high commitment and loyalty to their networks and, if an organization is composed of individuals with similar backgrounds, who easily form one big closed network within the organization, a top manager may be able to exercise strong leadership to bind all the organizational members.

However, it may not work in the current fast-changing environment. The current fast-changing, uncertain environment becomes threatening to organizational survival and innovation becomes one of the most inevitable management strategies to respond to the environment (Ryu and Lee, 2013). However, bonding social capital is vulnerable to innovation. Because individuals with bonding social capital share similar ideas within the closed networks, they are limited in the production of new ideas or in acceptance of alternative ways of getting things done from the outside (Nahapiet and Ghoshal, 1998; Janis, 1982; Perrow, 1984; Turner, 1976). Nahapiet and Ghoshal (1998) claim that closed networks produce “collective blindness that sometimes has disastrous consequences” (245).

The problem becomes more serious when top managers, as decision makers, rely on bonding social capital. As top managers depend on information from closed networks to make decisions, the decisions may become narrow-minded and cannot 
effectively respond to the changing environment. Another downside of bonding social capital is its economic inefficiency. Granovetter (1973) argues that members of a closed network share similar information so that even if a member of the network has multiple channels, the information the member receives is redundant. Also, a closed network limits a member of the network from cross-checking the reliability of the information because most members in the closed network share similar information. Moreover, due to its exclusiveness and inward-looking social relationship, bonding social capital can lead to out-group hostility (Coffe and Geys, 2007). That is, bonding social capital may help in developing high levels of trust and reciprocity among members of a closed network but it can also generate an "us-versus-them” approach, which results in distrust toward members of other networks (Abrams, Hogg and Marques, 2005; Coffe and Geys, 2007; Münster, 2007; Portes, 1998). As a result, top mangers' bonding social capital may lead to ineffective organizational operation and negatively influence organizational outcomes.

Hypothesis 1: A manager's bonding social capital may be negatively associated with organizational performance

\section{Bridging Social Capital and Organizational Performance}

Characteristics and the associated effects of bridging social capital are quite opposite to those of bonding social capital. According to Putnam (2000), bridging social capital is a set of networks among individuals with a heterogeneous background that crosscuts diverse external actors/networks. Thus, bridging social capital is outward looking, and covers diverse people and networks, which generate broader identities and reciprocity (Putnam, 2000). As a result, the bridging social capital helps in 
reducing in-group bias as well as extending social interaction to include out-group members (Marshall and Stolle, 2004).

In contrast to bonding social capital, it is often argued that bridging social capital is more likely to produce beneficial externalities (Coffe and Geys, 2007). For instance, Marshall and Stolle (2004) point out that bonding social capital prohibits members of a closed network from developing and transferring generalized trust to members of other networks, which leads to isolation from the broader community. However, bridging social capital enables them to develop and share trust with dissimilar individuals, which extends the boundary of the network (Marshall and Stolle, 2004). Its openness and extendibility allow individuals in one network to be able to share new, different ideas with individuals in different networks so that innovation can diffuse from one network to another. As a result, bridging social capital benefits not only members of their own network but also a broader community in which sets of networks are connected (Burt, 1992; Nahapiet and Ghoshal, 1998).

Moreover, bridging social capital creates a competitive advantage by linking two or more networks which otherwise would not be linked (Burt, 2001). The structural position that links two or more networks which otherwise are not linked is similar to the concept of Burt's (1992) structural hole. The structural hole between two networks does not necessarily mean that the two are not aware of each other; rather, they focus on their own network without giving attention to the other network (Burt, 2002). Thus, individuals situated in the structural hole position play a gatekeeper role by buffering or brokering their networks to other networks. Those individuals possess a high level of bridging social capital. Individuals at the structural hole position have a competitive advantage with respect to the access of new information from diverse contacts and a control advantage by bridging two other 
networks (Burt, 2001; 2002). By comparing two arguments about social capital network closure and structural holes - Burt (2001) concludes that both have competitive advantages over the other, but structural holes lead to better performance by adding values on bridging across the holes. Thus, it can be hypothesized as follows:

Hypothesis 2: A manager's bridging social capital will enhance organizational performance

\section{SOCIAL CAPITAL IN A TIME OF FINANCIAL DIFFICULTIES}

Social connection is not mere contacts; rather, it is intense involvement with high levels of reciprocity (Putnam, 2000). To exemplify this relationship, Putnam (2000) refers to Yogi Berra’s definition of reciprocity: “If you don’t go to somebody’s funeral, they won't come to yours” (20). A social network is composed of nodes and ties, but not all nodes and ties are equal. It depends on how strongly connected they are. One can say, “your real friends are those who show up at your funeral.” That is, individuals connected with strong ties hold a dedicated relationship to help one another when any member is in trouble. This is the strength of a strong tie.

Krackhardt’s (1992) “strength of strong tie” is to respond to Granovetter’s (1973) "strength of weak tie”. Granovetter (1973) points out that most studies focus on the impacts of strong ties but he sees the other side of strong ties. He argues that strong ties make dense networks, which only concentrate on relationships within a closed network. As a result, one's connectedness is confined. However, according to Granovetter, weak ties form less dense networks and individuals with weak ties can bridge individuals from different networks. Therefore, weak ties can expand one’s 
reach to other networks and access to information and resources that are not otherwise available (Granovetter, 1973).

However, weak ties can play a limited role in a time of difficulties. The social relationship based on weak ties is shallow and fragile. When resources are scarce and positions are insecure, individuals may hesitate to share their scarce resources with others. Individuals tied weakly share a relatively low level of trust and they cannot guarantee the rule of reciprocity when everyone is suffering. In such a situation, individuals tied strongly can benefit because they are easily available and greatly motivated to help one another (Granovetter, 1973; Krachhardt, 1992). Krackhardt (1992) also posits that no one is comfortable with a crisis but individuals tied strongly share a high level of trust and help one another to overcome a crisis.

Discussion on weak ties and strong ties may give some clues of the effects of bridging and bonding social capital. Granovetter (1973) claims “except under unlikely conditions, no strong tie is a bridge. (...) rather, [is that] all bridges are weak ties” (1364). Bonding social capital is developed based on similar backgrounds and produces strong brotherhood or sisterhood among members of a closed network, which enhances high levels of trust and norms of obligations and expectation, which may be hardly observed among people with bridging social capital (Coleman, 1988; Putnam, 2000). Thus, unlike bridging social capital, bonding social capital provides people in crisis with psychological, social and even financial support (Coffe and Geys, 2007; Putnam, 2000; Putnam and Gross, 2002).

In sum, although bridging (bonding) social capital is more (less) likely to enhance organizational performance, its impact is contingent on the situation of the environment that the social structure faces. When the social structure exists in a time 
of difficulties, the opposite effects may be plausible. Thus, this study hypothesizes as following:

Hypothesis 3: A manager's bonding social capital will enhance organizational performance in a time of difficulties.

Hypothesis 4: A manager's bridging social capital will decrease organizational performance in a time of difficulties.

\section{THE MODEL}

O’Toole and Meier (1999) have developed a contingent model of public management to predict organizational performance. The model predicts organizational performance with organizational stability, internal management and external management in addition to organizational environment and the previous performance as following:

$$
a_{t}=\beta_{1}\left(S+M_{1}\right) \times a_{t-1}+\beta_{2}\left(\frac{x_{t}}{s}\right) \times\left(\frac{M_{z}}{M_{4}}\right)+\theta_{t}
$$

where $o_{t}$ and $o_{t-\text { : }}$ are organizational performance at time t and time t-1 respectively; S denotes organizational stability;

$M_{1}$ is a management effort to manage the organization;

$X_{t}$ is environmental shocks at time $\mathrm{t}$;

$M_{2}$ and $M_{4}$ are management efforts to exploit environmental resources and to buffer environmental threats respectively; and $e_{t}$ is some random shocks.

$\beta_{1}$ and $\beta_{2}$ are estimateable parameters.

Social capital corresponds to managerial interactions with environmental actors in this model, and it has two forms- bonding and bridging social capital. Since 
this study focuses on social capital, this study modifies its original form into the following way:

$$
O_{t}=\beta_{1} O_{t-1}+\beta_{2} S C_{b d t}+\beta_{8} S C_{b r}+\beta_{4} X_{f}+\beta_{8} X_{t}+e_{t}
$$

where $O_{t}$ and $O_{t-\text { : }}$ are organizational performance at time t and time t-1 respectively; $S C_{b d}$ is bonding social capital;

$S C_{b r}$ is bridging social capital;

$X_{f}$ is a measure of environmental difficulty (financial difficulty);

$X_{\mathrm{t}}$ is all other environmental shocks at time t; and

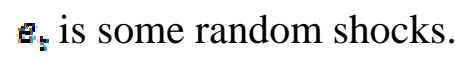

$R_{1}$ through $R_{\mathrm{g}}$ are estimateable parameters.

In this model, financial difficulty is included to operationalize a measure of environmental difficulty. More explanation will follow in the next section.

\section{DATA, VARIABLES AND SAMPLE}

This study draws a large sample from the Texas K-12 education system. School districts in Texas provide a unique opportunity to analyze the effects of top managers’ social capital in several ways. First, an education sector is one of the most representative public sectors in the United States. As a single sample, the Texas school districts are quite a big representation, and "the most common public organization in the United States” (Meier and O’Toole, 2009: 7). More than 1 percent of all governmental officials of any type in the United States are involved in the Texas school districts (Meier and O’Toole, 2009). Moreover, superintendents of school districts in Texas exercise autonomous discretion in taxation and personnel matters. Developing social capital depends on superintendents and superintendents are responsible for the management of school districts. However, school districts are highly professionalized and decentralized and give more substantial discretion to 
street-level bureaucrats (teachers) than any other public organizations; thus, any findings from this study need careful generalizations.

Data are drawn from two sources. The first source is from the Superintendent Management Survey conducted in the academic years 2002-2003 and 2005-2006. This survey is a part of an ongoing research project by O’Toole and Meier (for more information about data and instruments, see Meier and O’Toole (2007)). It concerns a superintendent's interaction with external actors in addition to leadership and management styles. The second source is from the Texas education agency, which provides information on a district's financial and personnel resources as well as students’ information.

\section{Organizational Performance}

This study analyzes students' average pass rates of the Texas Assessment of Knowledge and Skills (TAKS) as a school district's organizational performance. The TAKS is a statewide annual exam and for students to advance from the lower grade to the upper grade, students should pass the exam. As a result, the TAKS is one of the most critical performance measures for superintendents and superintendents as well as communities base their district's performance on the TAKS.

\section{Bonding Social Capital}

Bonding social capital is a set of networks with people of similar background (Putnam, 2000). To operationalize bonding social capital, this study focuses on a superintendent's frequent interaction with other superintendents, school board, principals and the Texas education agency. Although some focus on similar socioeconomic characteristics to measure bonding social capital (Coffe and Geys, 2007; Putnam, 2000), a network of members whose professional interests are similar also forms bonding social capital. In this sense, superintendents as well as other 
superintendents, school boards, principals and the Texas education agency develop a bonding social capital with special attention to education matters.

Superintendents are asked how frequently they interact with other superintendents, school boards, principals and the Texas education agency respectively and the responses range from never $(=1)$ to daily $(=6)$. The four variables are summed to generate one variable to denote bonding social capital. ${ }^{1}$

\section{Bridging Social Capital}

According to Putnam (2000), bridging social capital is an association with members with dissimilar backgrounds. To capture the characteristics of bridging social capital, this study also utilizes frequencies of superintendents' interaction with state legislatures, teachers associations, parental groups, and local business leaders, who are environmental actors. These groups are either political groups or interest groups that mostly capture bridging social capital (Putnam, 2000).

Similar to bonding social capital, the bridging social capital variable is generated with the sum of superintendents' frequent interaction with state legislatures, teachers associations, parental groups and local business leaders. ${ }^{2}$

\section{Environmental Difficulty}

To capture an environmental difficulty, this study focuses on a financial difficulty. Each school district generates revenues and utilizes revenue as their financial resources. Minor fluctuation of annual revenue may not cause serious problems, but big leaps, especially big losses of revenues as compared to the previous year, gives superintendents difficulties in managing their school districts. Sudden loss of revenue

\footnotetext{
${ }^{1}$ A principal-component factor analysis is also conducted to generate a factor score and it is found that the four variables are loaded on only one factor with an Eigen value of 1.53 . When a factor score is used as an independent variable, similar results are found.

${ }^{2}$ A principal-component factor analysis is also conducted to generate a factor score and it is found that the four variables are loaded on only one factor with an Eigen value of 1.70 . When a factor score is used as an independent variable, similar results are found.
} 
is something that superintendents should definitely manage and it is good in a research context to see how bonding and bridging social capital interact with a financial difficulty.

To measure a financial difficulty, revenue per pupil is regressed on year, and its residual is drawn. The positive values of the residual mean more revenue per pupil than the expected level while negative values of the residual refers to less revenue per pupil than the expected revenue. Because the variable represents financial difficulty, not opportunity, the residual is reversed by multiplying the original residual by -1 .

\section{Control Variables}

In addition to the main independent variable of interests, this study controls for student composition (percentage of student's ethnicity and percentage of low-income students), teacher’s information (average teacher's experience, average teacher's salary, and teachers' turnover rates) and school district information (class size, instructional expenditure per pupil and lagged TAKS rates).

\section{FINDINGS}

Table 1 shows descriptive statistics and correlation coefficients among variables. From the correlation analysis, it is found that bonding social capital and bridging social capital are positively correlated, but its correlation coefficient is quite low $(\mathrm{r}=0.39, \mathrm{p}<0.000)$. The results are interesting for two reasons. First, they are not negatively correlated. In other words, a superintendent’s developing bonding social capital does not negate his/her developing bridging social capital. Second, nonetheless, they are weakly correlated, which means they are distinct measures.

Among others, the dependent variable and its lagged variable is highly correlated ( $r=0.92, \mathrm{p}<0.000)$. It supports O’Toole and Meier's (1999) model that an organization has inertia so that current performance is pretty much predicted by its 
previous performance. It later leads to a high value of R-squared in the analysis. Once a lagged variable is controlled, there remains limited room for other variables to explain the variation of the dependent variable. Thus, any statistically significant findings from the analyses can be interpreted as significant predictors for the dependent variable.

[Table 1 about here]

Table 2 shows the results of the weighted least square analyses. ${ }^{3}$ Model 1 in the table finds that the coefficient for bonding social capital is negative and statistically significant (t-statistics: -2.66). That is, a superintendent’s bonding social capital is negatively associated with a district's performance. The opposite is found for bridging social capital in Model 1. The coefficient for bridging social capital is positive and statistically significant (t-statistics: 4.46), which indicates that a superintendent's bridging social capital enhances a school district’s performance. As previous studies on social capital argue, bonding social capital is limited to the acceptance of new ideas and circulates redundant resources while bridging social capital is open to networks with different ideas and various resources being shared. As a result, organizations may benefit more from a top manager's bridging social capital. These findings support the first two hypotheses of this study.

In addition to bonding and bridging social capital, financial difficulty is found to be negatively associated with the organizational performance although its statistical power is weak (t-statistics: -1.89). That is, as revenue per pupil gets lower than its expected value, a school district doesn't achieve better performance.

However, Model 2 in the table shows that bonding and bridging social capital in different ways moderate negative impacts of financial difficulty. The coefficient for

\footnotetext{
${ }^{3}$ Results of the OLS meet all Gauss-Markov assumptions except the homoscedasticity assumption. To correct heteroskedasticity, a weighted least square analysis was used as recommended by Wooldridge (2009).
} 
interaction terms between bonding social capital and financial difficulty is 0.147 with t-statistics of 3.41. While the impact of bonding social capital is negative and statistically significant (t-statistics: -4.08) in Model 2, its interaction term with financial difficulty is positively associated with TAKS pass rates. Findings for bridging social capital are just the opposite; the interaction term between bridging social capital and financial difficulty is negatively associated with TAKS pass rates (tstatistics: -2.41). That is, a superintendent's bonding social capital reduces the negative impacts of financial difficulty. In a time of financial difficulty, bridging social capital represented by weak ties may be fragile. A social relationship between two actors is reciprocal in that one can get returns from the other by providing the other with something that the other wants. If an organization suffers from financial difficulty, the most necessary resources for the organization may be financial aid. However, financial support, if it is voluntary, may require a high threshold of reciprocity and those who are linked with weak ties may not support one another as compared to those who are connected with strong ties. Thus, one can benefit more from his/her bonding social capital than bridging social capital when one faces a financial difficulty.

[Table 2 about here]

Table 3 shows impact of bonding and bridging social capital on other performance measures of school districts. Overall, financial difficulty is not statistically significantly associated with the average scores of ACT, SAT, the percentage of students who score above 1110 on SAT and the percentage of students who were admitted to college. It is found that financial difficulty is not statistically significant for those performance measures. It may not be surprising because revenue aims at day-to-day operation, which is more associated with annual statewide TAKS 
performance for all students. Insignificant statistical results of financial difficulty make it hard to test the moderating role of bonding and bridging social capital. However, models without interaction terms consistently confirm the negative impacts of bonding social capital and positive impacts of bridging social capital. It reminds us again that bridging social capital improves organizational performance while bonding social capital can lead to lower organizational performance. If different environmental difficulties are included, it is worthwhile to test moderating roles of bonding and bridging social capital. Future research needs to follow in this sense.

Then, the next question is, how do superintendents develop/manage their social capital? The following section will discuss a possible answer.

[Table 3 about here]

\section{CONCLUSION AND DISCUSSION}

Organizations require various types of resources to get things done. Monetary resources is a representative example. Humans in the organizations are also treated as important resources. Knowledge, skills, or abilities (KSA) of individuals within the organization determine the success of the organization (Lim, Mathis and Jackson, 2010). Social capital goes further than the concept of human capital or human resources. Social capital focuses on not only an individual's KSA but also the relations that the individual holds. By being linked with others who possess what one needs, one can easily gain access to what one needs. It changes from the world of know-how to the world of know-whom.

As reviewed, there are at least two types of know-who; bonding and bridging social capital. Bonding social capital links people with similar backgrounds so that ties among people in networks are strong (Putnam, 2000). Bridging social capital linking people with different backgrounds develops weak but diverse ties among 
participants (Putnam, 2000). Both have pros and cons. In a sense that new ideas and different resources can circulate among diverse networks, bridging social capital can be more beneficial for organizations than bonding social capital. However, network participants with similar backgrounds tend to develop strong ties and they firmly bond their relationships to buffer each other from environmental shocks. Findings of this study reveal impacts of bonding and bridging social capital and their moderating role on organizational performance contingent on the level of financial difficulty.

Finding that bridging (bonding) social capital positively (negatively) influences organizational performance while its moderating role with financial difficulty negatively (positively) affects organizational performance, what can be the recommendation for top managers? The answer may depend on the situation that the organization faces and the qualification of a top manager who can accurately analyze the situation. To bond or to bridge is not an “either-or” question (Putnam, 2000. p.23), Rather, according to Putnam (2000), it is a matter of “more or less” (23). Bonding and bridging social capital is like the two opposite edges of a sword. Too much attention on one aspect of social capital in a time of peace can leads to failure of an organization in a time of difficulty. Thus, a top manager has to balance skillfully between bonding and bridging social capital.

In fact, bonding and bridging social capital is positively correlated as shown in Table $1(\mathrm{r}=.39, \mathrm{p}<.000)$. That is, a superintendent's developing bonding social capital does not necessarily mean loss of bridging social capital, or vice versa. Thus, it is a top manager's critical role to balance bonding and bridging social capital contingent on the degree to which his/her organization faces difficulty.

For more concrete knowledge about the impacts of social capital, this study suggests that more refined measures of bonding and bridging social capital in 
different contexts of public organizations need to follow. Moreover, in addition to financial difficulty, other types of environmental shocks need to be used to confirm the moderating role of bonding and bridging social capital.

Although findings of this study need further empirical confirmation from future research, it is expected to make a theoretical contribution to the body of literature on social capital in the context of public organizations. 
Reference

Abrams, Dominic , Michael A. Hogg, and Jose Marques. 2005. The Social Psychology of Inclusion and Exclusion. New York, NY: Psychology Press.

Bourdieu, Pierre. 1985. "The Forms of Capital." In Handbook of Theory and Research for the Sociology of Education, edited by John Richardson, 241-258. New York: Greenwood.

Burt, Ronald S. 1992. Structural Holes. Cambridge, MA: Harvard University Press.

Burt, Ronald S. 2001. "Structural Holes versus Network Closure as a Social Capital." In Social Capital: Theory and Research, edited by Nan Lin, Karen Cook and Ronald S. Burt. New York: Aldine de Gruyter.

Burt, Ronald S. 2002. "The Social Capital of Structural Holes." In New Directions in Economic Sociology, edited by Mauro Guillen, Randall Collins, Paula England and MarshallW Meyer. New York, NY: Russell Sage Foundation.

Coffé, Hilde, and Benny Geys. 2007. "Toward an Empirical Characterization of Bridging and Bonding Social Capital." Nonprofit and Voluntary Sector Quarterly 36 (1):121-139.

Coleman, James. 1988. "Social Capital in the Creation of Human Capital." American Journal of Sociology 94:s95-s120.

DeFilippis, James. 2001. "The myth of social capital in community development." Housing Policy Debate 12 (4):781-806.

Foley, Michael W. , and Bob Edwards. 1998. "Beyond Tocqueville: Civil Society and Social Capital in Comparative Perspective." American Behavioral Scientist 42 (5):5-20.

Granovetter, Mark S. . 1973. "The Strength of Weak Ties." American Journal of Sociology 78 (6):1360-1380.

Halpern, David. 2005. Social Capital. Cambridge, UK: Polity.

Janis, Irving. 1982. Groupthink: Psychological Studies of Policy Decisions and Fiascos. Boston, MA: Houghton Mifflin.

Krackhardt, David. 1992. "The Strength of Strong Ties: The Importance of Philos in Organizations." In Networks and Organizations: Structure, Form, and Action, edited by Nitin Nohria and Robert G. Eccles, 216-239. Boston, MA: Harvard Business School Press.

Marschall, MelissaJ, and Dietlind Stolle. 2004. "Race and the City: Neighborhood Context and the Development of Generalized Trust." Political Behavior 26 (2):125-153.

Meier, Kenneth J. , and Laurence J. O'Toole. 2009. "The Proverbs of New Public Management: Lessons from and Evidence-based Research Agenda." The American Review of Public Administration 39 (1):4-22.

Meier, Kenneth J., and Laurence J. O'Toole. 2007. "Modeling Public Management: Empirical Analysis of the Management-Performance Nexus." Public Management Review 9 (4):503-527.

Münster, Johannes. 2007. "Simultaneous inter- and intra-group conflicts." Economic Theory 32 (2):333-352.

Nahapiet, Janine, and Sumantra Ghoshal. 1998. "Social Capital, Intellectual Capital, and the Organizational Advantage." Academy of Management Review 23 (2):242-266.

O'Toole, Laurence J., and Kenneth J. Meier. 1999. "Modeling the Impact of Public Management: Implications of Structural Context." Journal of Policy Analysis and Management 9 (4):505-526. 
Olson, Mancur. 1982. The Rise and Decline of Nations: Economic Growth, Stagflation, and Social Rigidities. New Haven, CT: Yale University Press.

Perrow, Charles B. 1984. Normal Accidents: Living with High Risk Technologies. New York, NY: Basic Books.

Portes, Alejandro. 1998. "Social Capital: Its Origins and Applications in Modern Sociology." Annual Review of Sociology 24.

Putnam, Robert. 2000. Bowling Alone: The Collapse and Revival of American Community. New York, NY: Simon\&Schuster Paperbacks.

Putnam, Robert. 2002. "Introduction." In Democracies in Flux: The Evolution of Social Capital in Contemporary Society, edited by Robert Putnam and Kristin Goss, 1-19. Oxford, UK: Oxford University Press.

Turner, Barry A. 1976. "The Organizational and Interorganizational Development of Disasters." Administrative Science Quarterly 21 (3):378-397. 
Table 1. Descriptive Statistics and Correlation Coefficient

\begin{tabular}{|c|c|c|c|c|c|c|c|c|c|c|c|c|c|c|c|}
\hline & (1) & $(2)$ & (3) & (4) & (5) & $(6)$ & $(7)$ & (8) & (9) & $(10)$ & $(11)$ & $(12)$ & $(13)$ & $(14)$ & $(15)$ \\
\hline (1)TAKS Pass Rates & 1.00 & & & & & & & & & & & & & & \\
\hline (2)Bonding Social Capital & 0.12 & 1.00 & & & & & & & & & & & & & \\
\hline (3)Bonding Social Capital X Financial Difficulty & 0.03 & -0.07 & 1.00 & & & & & & & & & & & & \\
\hline (4)Bridging Social Capital & -0.05 & 0.39 & -0.01 & 1.00 & & & & & & & & & & & \\
\hline (5)Bridging Social Capital X Financial Difficulty & 0.02 & -0.09 & 0.98 & 0.01 & 1.00 & & & & & & & & & & \\
\hline (6)Financial Difficulty & 0.03 & -0.09 & 0.99 & -0.01 & 0.98 & 1.00 & & & & & & & & & \\
\hline (7)\% Black Student & -0.21 & -0.07 & 0.13 & 0.06 & 0.15 & 0.14 & 1.00 & & & & & & & & \\
\hline (8)\% Hispanic Student & -0.26 & -0.06 & -0.05 & 0.05 & -0.05 & -0.06 & -0.19 & 1.00 & & & & & & & \\
\hline (9)\% Low-income Student & -0.44 & 0.01 & -0.10 & 0.03 & -0.11 & -0.10 & 0.17 & 0.65 & 1.00 & & & & & & \\
\hline (10)Teacher's Experience & 0.23 & 0.11 & -0.09 & 0.05 & -0.10 & -0.10 & -0.13 & -0.07 & -0.08 & 1.00 & & & & & \\
\hline (11)Teacher's salary (x 1000) & 0.08 & -0.11 & -0.03 & 0.17 & -0.01 & -0.03 & 0.01 & 0.17 & -0.15 & 0.37 & 1.00 & & & & \\
\hline (12)\% Teacher Turnover & -0.36 & -0.04 & -0.09 & -0.08 & -0.08 & -0.09 & 0.18 & 0.09 & 0.20 & -0.43 & -0.32 & 1.00 & & & \\
\hline (13)Class Size & -0.12 & -0.18 & 0.55 & 0.08 & 0.56 & 0.56 & 0.18 & 0.12 & -0.07 & -0.19 & 0.30 & 0.00 & 1.00 & & \\
\hline (14)Per Pupil Instructional Expenditure & -0.17 & 0.07 & -0.81 & 0.02 & -0.80 & -0.83 & -0.11 & 0.06 & 0.14 & 0.12 & 0.05 & 0.10 & -0.65 & 1.00 & \\
\hline (15)Lagged TAKS & 0.92 & 0.14 & 0.01 & -0.04 & 0.01 & 0.01 & -0.25 & -0.31 & -0.52 & 0.28 & 0.12 & -0.38 & -0.13 & -0.12 & 1.00 \\
\hline Mean & 73.44 & 17.15 & 5.38 & 11.29 & 3.80 & 0.34 & 8.93 & 30.25 & 49.72 & 12.20 & 37.09 & 18.16 & 12.80 & 4242.61 & 75.83 \\
\hline Std. Dev. & 16.74 & 2.09 & 41.59 & 2.38 & 27.56 & 2.38 & 12.85 & 26.11 & 19.14 & 2.50 & 3.05 & 9.07 & 2.50 & 1097.84 & 13.26 \\
\hline Min & 6 & 10 & -694.72 & 5 & -451.57 & -34.74 & 0 & 0 & 0 & 0.25 & 22.27 & 0 & 3.60 & 226 & 16 \\
\hline Max & 100 & 24 & 115.24 & 23 & 64.02 & 6.40 & 100 & 100 & 99.30 & 19.35 & 49.02 & 77.78 & 33.87 & 15066 & 100 \\
\hline
\end{tabular}

$\mathrm{N}=1235$ 
Table 2. Impact of Bonding and Bridging on Organizational Performance

\begin{tabular}{|c|c|c|}
\hline \multirow{2}{*}{ VARIABLES } & Model (1) & Model (2) \\
\hline & Coefficient & Coefficient \\
\hline Bonding Social Capital & $\begin{array}{c}-0.136 * * * \\
(0.051)\end{array}$ & $\begin{array}{c}-0.302 * * * \\
(0.074)\end{array}$ \\
\hline Bonding Social Capital X Financial Difficulty & & $\begin{array}{c}0.147^{* * *} \\
(0.043)\end{array}$ \\
\hline Bridging Social Capital & $\begin{array}{c}0.234 * * * \\
(0.052)\end{array}$ & $\begin{array}{c}0.276 * * * \\
(0.066)\end{array}$ \\
\hline Bridging Social Capital X Financial Difficulty & & $\begin{array}{c}-0.094 * * \\
(0.039)\end{array}$ \\
\hline Financial Difficulty & $\begin{array}{l}-0.225^{*} \\
(0.119)\end{array}$ & $\begin{array}{c}-1.695 * * \\
(0.719)\end{array}$ \\
\hline \% Black Student & $\begin{array}{c}-0.008 \\
(0.010)\end{array}$ & $\begin{array}{c}-0.057 * * * \\
(0.011)\end{array}$ \\
\hline \% Hispanic Student & $\begin{array}{c}0.005 \\
(0.008)\end{array}$ & $\begin{array}{l}-0.004 \\
(0.008)\end{array}$ \\
\hline \% Low-income Student & $\begin{array}{c}-0.059 * * * \\
(0.011)\end{array}$ & $\begin{array}{c}-0.027 * * \\
(0.012)\end{array}$ \\
\hline Teacher's Experience & $\begin{array}{l}0.112 * \\
(0.059)\end{array}$ & $\begin{array}{c}-0.144 * * * \\
(0.055)\end{array}$ \\
\hline Teacher's salary (x1000) & $\begin{array}{l}-0.069 \\
(0.061)\end{array}$ & $\begin{array}{c}0.177 * * * \\
(0.068)\end{array}$ \\
\hline \% Teacher Turnover & $\begin{array}{c}-0.056 * * * \\
(0.018)\end{array}$ & $\begin{array}{c}-0.078 * * * \\
(0.019)\end{array}$ \\
\hline Class Size & $\begin{array}{l}-0.052 \\
(0.104)\end{array}$ & $\begin{array}{c}-0.474 * * * \\
(0.108)\end{array}$ \\
\hline Per Pupil Instructional Expenditure & $\begin{array}{c}-0.001^{* *} \\
(0.000)\end{array}$ & $\begin{array}{c}-0.002 * * * \\
(0.000)\end{array}$ \\
\hline Previous Year's TAKS Pass Rate & $\begin{array}{c}0.815^{* * * *} \\
(0.017)\end{array}$ & $\begin{array}{c}0.833 * * * \\
(0.016)\end{array}$ \\
\hline 2005.year & $\begin{array}{c}-11.936 * * * \\
(0.400)\end{array}$ & $\begin{array}{c}-11.213^{* * *} \\
(0.346)\end{array}$ \\
\hline Constant & $\begin{array}{c}26.844^{* * *} \\
(3.167)\end{array}$ & $\begin{array}{c}30.474 * * * \\
(3.323)\end{array}$ \\
\hline Observations & 1,008 & 1,016 \\
\hline R-squared & 0.960 & 0.946 \\
\hline Adjusted R-squared & 0.960 & 0.945 \\
\hline
\end{tabular}


Table 3. Other Performance Measure

\begin{tabular}{|c|c|c|c|c|c|c|c|c|}
\hline & ACT & ACT & SAT & SAT & SAT1110 & SAT1110 & College Pass & College Pass \\
\hline Bonding Social Capital & $\begin{array}{l}-0.037 * \\
(0.022)\end{array}$ & $\begin{array}{l}-0.030 \\
(0.024)\end{array}$ & $\begin{array}{l}-1.961 \\
(1.216)\end{array}$ & $\begin{array}{l}-0.956 \\
(1.524)\end{array}$ & $\begin{array}{l}-0.630 * * * \\
(0.178)\end{array}$ & $\begin{array}{l}-0.762 * * * \\
(0.196)\end{array}$ & $\begin{array}{l}-0.328 * \\
(0.168)\end{array}$ & $\begin{array}{l}-0.272 \\
(0.181)\end{array}$ \\
\hline Bridging Social Capital & $\begin{array}{l}0.041 * * \\
(0.019)\end{array}$ & $\begin{array}{l}0.038^{*} \\
(0.020)\end{array}$ & $\begin{array}{l}1.740 \\
(1.080)\end{array}$ & $\begin{array}{l}0.769 \\
(1.210)\end{array}$ & $\begin{array}{l}0.385^{* *} \\
(0.155)\end{array}$ & $\begin{array}{l}0.363^{* *} \\
(0.160)\end{array}$ & $\begin{array}{l}0.334 * * \\
(0.145)\end{array}$ & $\begin{array}{l}0.292^{*} \\
(0.149)\end{array}$ \\
\hline Financial Difficulty & $\begin{array}{l}-0.024 \\
(0.034)\end{array}$ & $\begin{array}{l}0.076 \\
(0.196)\end{array}$ & $\begin{array}{l}-1.726 \\
(2.626)\end{array}$ & $\begin{array}{l}2.992 \\
(15.778)\end{array}$ & $\begin{array}{l}0.309 \\
(0.320)\end{array}$ & $\begin{array}{l}-3.874^{* *} \\
(1.841)\end{array}$ & $\begin{array}{l}0.012 \\
(0.245)\end{array}$ & $\begin{array}{l}0.385 \\
(1.469)\end{array}$ \\
\hline Bonding Social Capital X Financial Difficulty & & $\begin{array}{l}-0.009 \\
(0.012)\end{array}$ & & $\begin{array}{l}-1.111 \\
(0.964)\end{array}$ & & $\begin{array}{l}0.183 \\
(0.112)\end{array}$ & & $\begin{array}{l}-0.077 \\
(0.091)\end{array}$ \\
\hline Bridging Social Capital X Financial Difficulty & & $\begin{array}{l}0.005 \\
(0.010)\end{array}$ & & $\begin{array}{l}1.259 * \\
(0.733)\end{array}$ & & $\begin{array}{l}0.093 \\
(0.085)\end{array}$ & & $\begin{array}{l}0.090 \\
(0.074)\end{array}$ \\
\hline Observations & 1,065 & 1,065 & 891 & 891 & 1,054 & 1,054 & 1,121 & 1,121 \\
\hline R-squared & 0.414 & 0.414 & 0.340 & 0.342 & 0.312 & 0.316 & 0.328 & 0.329 \\
\hline
\end{tabular}

Standard errors in parentheses

*** $\mathrm{p}<0.01, * * \mathrm{p}<0.05, * \mathrm{p}<0.1$ 